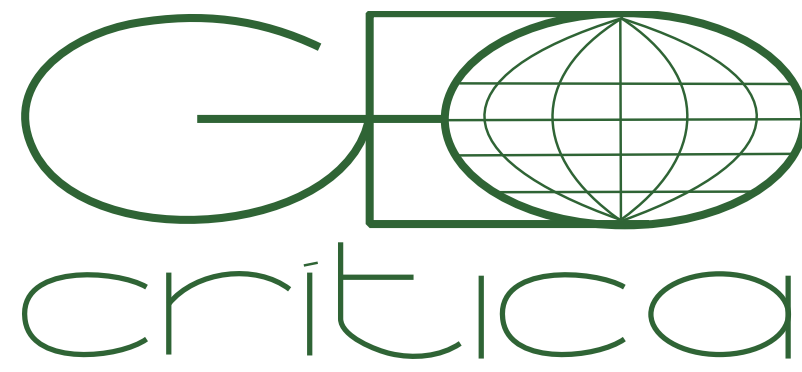

\section{Scripta Nova}

Revista Electrónica de Geografía y Ciencias Sociales Universitat de Barcelona

ISSN: $1138-9788$

Vol. 25, Núm. 2 (2021), p. 241-270

\title{
(DES)ENCUENTROS DE CHICAGO: ECOLOGIA HUMANA Y MORFOLOGIA SOCIAL EN LA PERSPECTIVA DE MAURICE HALBWACHS
}

\section{Emilio Martínez}

(Des)encuentros de Chicago: ecología humana y morfología social en la perspectiva de Maurice Halbwachs (Resumen)

Distintos autores en el campo de los estudios urbanos y demográficos han planteado una correspondencia analítica y temática entre la ecología humana de la escuela de Chicago y la morfología social de la escuela durkheimiana. A partir de la estancia del sociólogo francés Maurice Halbwachs en el Departamento de Sociología de Chicago en el otoño de 1930 se aborda el alcance del intercambio de perspectivas analíticas, la reciprocidad y las divergencias existentes entre ambos modos de considerar los procesos urbanos. Se trata de un estudio teórico basado en textos y documentos con el fin de ponderar el valor de esta recepción y si acaso impactó en la conceptualización subsiguiente de los procesos socio-espaciales, en sus maneras de trabajar y en la construcción disciplinar.

Palabras clave: morfología social/ecología urbana/ Chicago/ Análisis urbano/ recepción disciplinar/ Halbwachs

\section{Chicago convergences and divergences: on human ecology and social morphology in Halbwachs' approach (Abstract) \\ Different critics on urban and demographic studies have proposed an analytical and thematic correspondence between the human ecology of the Chicago school and the social morphology of the Durkheimian school. The research stay of the French sociologist Maurice Halbwachs in the Chicago Department of Sociology in the autumn of 1930 may be an opportunity to study the exchange of analytical perspectives, reciprocity and divergences between both schools. This is a theoretical revision based on the analysis of texts and documents, in order to assess the scope of this reception.}

Key Words: social morphology/ urban ecology/ Chicago / Urban Analysis/ Reception 
La historia del desarrollo científico, en todos sus campos, contiene un capítulo siempre inconcluso destinado a dar cuenta de los intercambios intelectuales entre distintas tradiciones de pensamiento. En diferentes circunstancias los investigadores alineados en unas u otras escuelas se han visto llamados a contrastar sus planteamientos y métodos de trabajo con el fin de asegurar el refinamiento y la comprensión mutua de las propuestas analíticas en concurrencia. Esto parece especialmente oportuno en situaciones de crisis y restitución disciplinar. Eventualmente, cuando media un desplazamiento físico, los encuentros pueden obedecer además al interés de una de las partes por apreciar in situ la organización institucional de las actividades académicas e investigadoras de la otra y reforzar los vínculos.

Bajo ese prisma podemos contemplar la experiencia de Maurice Halbwachs como profesor visitante del Departamento de Sociología de la Universidad de Chicago durante el otoño de 1930 y la manera en que el encuentro con los académicos americanos ha sido interpretado en el ámbito disciplinar. No deja de ser llamativo que con su presencia en la ciudad del medio-oeste americano se emplazaron dos brillantes tradiciones del pensamiento sociológico: de un lado, la escuela de Chicago ${ }^{1}$ y de otro, la escuela francesa configurada en torno a Durkheim, que Halbwachs prolongaba con rigor y audacia ${ }^{2}$. De un modo más específico supuso la coincidencia de dos perspectivas analíticas que en el ámbito estricto de la sociología vinieron a enmarcar el estudio de los procesos urbanos durante buena parte del siglo XX: la ecología humana y la morfología social. Su ascendente en la historia disciplinar ha sido, sin embargo, desigual. La institucionalización de la sociología urbana como una rama específica del conocimiento sociológico se ha atribuido de ordinario a los trabajos de Robert E. Park y Ernst Burgess, que en Chicago desarrollaron un amplio y sistemático programa de investigaciones sobre la realidad urbana inmediata. Contaron además con los medios de difusión oportunos para su reconocimiento. Menos atención gozaron las investigaciones de Halbwachs al respecto, poseedor de una obra mucho más plural, aunque conforme se han ido redescubriendo sus estudios urbanos ha venido a ser apreciado como uno de los más finos intérpretes de las transformaciones sociomorfológicas de las metrópolis del siglo XX.

Halbwachs redactó dos artículos académicos derivados de su estancia ("Les budgets de familles ouvrières aux États-Unis”, 1931; “Chicago, expérience ethnique”, 1932) y ocho escritos sobre distintos aspectos de la vida americana publicadas en Le Progrès de Lyon entre octubre de 1930 y febrero de $1931^{3}$. Con tal bagaje y la publicación de "La sociologie en

\footnotetext{
1 Obviamos en este caso la cuestión relativa a la querella sobre la existencia o no de una escuela de pensamiento unitaria en el caso de Chicago que ha sido tratada ya por Chapouille (2001). En este caso nos referimos a la generación de investigadores que articulan la ecología urbana (Park, Burgess, McKencie...)

2 En rigor, otros durkheimianos lo habían precedido en los EE.UU., entre ellos Mauss y Bouglé, destacados en misiones de carácter institucional. Ambos procedieron como intermediarios de la estancia de Halbwachs: Bouglé fue quien, tras su regreso de Chicago, anunció a Halbwachs la invitación que recibiría del Departamento de Sociología para incorporarse unos meses. Y Mauss, mediante distintas misivas dirigidas a sus contactos (Burgess entre otros), allanó la estadía de Halbwachs.

3 El legado de Halbwachs sobre el universo social de los Estados Unidos incluye también la correspondencia privada relativa a esa experiencia y la conferencia "Budgets de familles aux États-Unis et en Allemagne", 1933. Todos estos escritos fueron reunidos por Christian Topalov en un volumen soberbio titulado Ecrits d'Amérique (2012) sobre el cual basamos buena parte de este trabajo y del que somos deudores.
} 
Allemagne et aux États-Unis" (1932) pasó a ser inmediatamente considerado un entendido en la sociología americana. Pero fue mucho más tarde cuando cobró fuerza su valor como introductor del programa chicagüense en Francia. Primero de forma tímida, elíptica incluso, al modo en que Chombart de Lauwe (1952) establecía una conexión entre ambas referencias teóricas; después, Gurvitch (1963) presentaría la morfología social como el antecedente de la ecología social. Esta acotación se impuso con la publicación de L'École de Chicago. Naissance de l'écologie urbaine (1979) de Joseph \& Grafmeyer, donde el artículo "Chicago, expérience ethnique" (1932) fue reivindicado como la primera reseña explícita de los planteamientos teórico-metodológicos de la escuela de Chicago y a su vez Halbwachs presentado como uno de los primeros lectores franceses de Park y Burgess. Desde esa concepción el texto fue incorporado al volumen de escritos seleccionados en la edición de Joseph \& Grafmeyer, valorando las correspondencias existentes entre ambos programas.

“(...) algunos de sus trabajos guardaban afinidad con el programa durkheimiano centrado sobre los conceptos de morfología social, de densidad "moral" y "física", de medio interno. Sin embargo, ni en Durkheim ni entre sus herederos directos con la notable excepción de Maurice Halbwachs esos marcos conceptuales alimentaron investigaciones empíricas encaminadas a estudiar en terrenos determinados los procesos sociales que intervienen en la evolución de los espacios urbanizados y los efectos de esta urbanización sobre la vida en sociedad" (Grafmeyer 2004,6)

Para Gilles Montigny $(2005,9)$ el artículo antedicho "sigue siendo en la actualidad uno de los mejores textos franceses de introducción a las prácticas científicas de la primera Escuela de Chicago". Un dictamen suscrito por Roncayolo, declarado discípulo postrero de Halbwachs, para quien no sólo éste "introdujo en la cultura francesa la ecología urbana de Chicago, sino que lo hizo acompañado de la crítica pertinente" (Chesneau y Roncayolo 2011, 93).

Mayor dedicación al examen del alcance de este intercambio lo encontramos en los estudios de Marcel (1999) y Topalov (2006, 2012), minuciosos y precisos, que nos sirven de guía. Todos estos escritos, junto con trabajos anteriores sobre Halbwachs y Park, habilitan el estudio de los paralelismos, la reciprocidad y las divergencias existentes entre ambos modos de afrontar el análisis de los procesos urbanos, así como los cauces, los tiempos y el valor de su recepción. Se trata de un estudio teórico basado en el análisis de textos y documentos, con el fin de cifrar si esta recepción fue o no mutua, y si acaso impactó después en la forma de analizar los procesos socio-espaciales de ambas tradiciones, en sus maneras de trabajar y en la propia construcción disciplinar. Sin duda, una comprensión más precisa de este intercambio intelectual exige emplazarlo en sus contextos sociales e institucionales, que le dan sentido, especialmente en lo relativo a las dificultades para la consolidación académica de la sociología y sus opciones metodológicas en aquellos momentos.

\section{De Estrasburgo a Chicago}

El viaje de Halbwachs a Chicago podría enmarcarse en esa insaciable curiosidad que fue uno de sus rasgos más sobresalientes y en la disposición franca al debate sereno con otras 
corrientes intelectuales, fueran del mismo o de otros campos disciplinares. Sus reseñas críticas (en las que destacó en número y calidad en distintas revistas) y sus viajes de estudios (Gotingen, Berlín y Viena) dan fe de ese talante abierto. Tal temperamento encontró un clima intelectual propicio en la Universidad de Estrasburgo, donde accedió a una carrera académica tardía y largamente ambicionada. La andanza americana de Halbwachs se acomoda también a la voluntad de restitución de los estudios sociológicos en Francia ante el agotamiento y las dificultades que mostraban entonces. En efecto, aunque nunca en primera línea del frente institucional, Halbwachs participó con Mauss y Bouglé en la reconstrucción del legado de l'Année sociologique en el marco de la renovación de la enseñanza superior e investigación de las ciencias sociales francesas en el período de entreguerras. Como veremos, la referencia americana estuvo muy presente en este empeño, no tanto en lo concerniente a los contenidos disciplinares como en lo relativo a las competencias organizativas, institucionales y financieras.

\section{La atmósfera intelectual de la Universidad alsaciana}

Halbwachs fue nombrado profesor de Sociología y Pedagogía en la Facultad de Letras de la Universidad de Estrasburgo en 19194, tras un nombramiento tardío como maître de conferences de filosofía en la Universidad de Caen (1918). John E. Craig (1979) y Annette Becker (2003) advierten al respecto que nada hay de azaroso en su designación. A los méritos de su trayectoria -que comprende una orientación germanófila-, al hecho de tener origen y apellido alsacianos (que en el contexto inmediato adquiría valor para sortear connotaciones "colonialistas"), se añade la intervención decisiva del exministro Albert Thomas sugiriendo la creación y el destinatario de la cátedra de Estrasburgo ${ }^{5}$. Era un escenario prometedor el de la recuperación francesa de la Alsacia, con la constitución de la nueva universidad francesa. Tras el cierre de la universidad alemana Kaiser Wilhelm (7 de diciembre de 1918) y la expulsión de sus profesores, la administración gala dispuso emplear el centro como instrumento de influencia cultural: la prosperidad y el predicamento de la institución habrían de afirmar el prestigio de la nación. Por esa razón se destinaron más recursos a Estrasburgo que a otras universidades de provincias y se cuidaron las medidas encaminadas a atraer hacia ella a profesores notables: mejores instalaciones, edificios, bibliotecas, remuneraciones y cátedras de nuevo cuño (Craig 1979). Junto a sus condiciones materiales, Estrasburgo destacó por su particular atmósfera intelectual, alejada del afectado habitus escolar de París. Entre los profesores, casi todos normalianos como Halbwachs, se sucedían los debates de

\footnotetext{
4 Esta cátedra conserva al principio el mismo nombre que la de Durkheim, pero en 1922 pasa a denominarse exclusivamente cátedra de Sociología, siendo la primera francesa propiamente denominada así. Georg Simmel había ocupado esta cátedra en la vieja universidad Kaiser Wilhelm; con la administración francesa tras la IGM es Halbwachs quien le sucede. En 1935, cuando Halbwachs se incorpora a la Sorbona en sustitución de Célestin Bouglé, su titularidad pasa a G. Gurvitch.

5 Desde la fundación del Grupo de Estudios Socialistas, que apoyaba a la corriente de Jean Jaurès en el partido socialista francés (SFIO) Halbwachs estuvo muy ligado a Albert Thomas, colaborando con él en l'Humanité, después en el gabinete ministerial (Thomas fue Ministro de Armamento durante la Primera Guerra Mundial) y en la OIT, de la que Thomas fue director general hasta su muerte en 1932. Thomas estaba interesado en el desarrollo de un instituto de estudios sobre el trabajo en Estrasburgo.
} 
ideas; se innovaba en las maneras docentes (asistían a los cursos de sus colegas o desarrollaban sesiones conjuntas); el intercambio de perspectivas analíticas era frecuente (las célebres "tertulias del sábado", tendentes a la confraternización y la discusión templada). Y en la línea de apertura y enriquecimiento intelectual a la que se aspiraba, se fomentó la realización de estancias de investigación en centros extranjeros (en esa época Halbwachs viajaría también a Palestina y a Estambul) así como un cierto grado de interdisciplinariedad.

Si Estrasburgo encarnaba el "espíritu de síntesis" evocado por Henri Berr en $1921^{6}$ no cabe duda de que Halbwachs lo administraba con generosidad. En el contexto fronterizo recuperó su vínculo con la sociología y las ciencias sociales alemanas. Respecto a las relaciones interdisciplinares, Halbwachs participaba activamente en múltiples aventuras intelectuales. Fue llamado a incorporarse en 1928 al consejo de redacción de la revista Annales d'historie économique et sociale de Lucien Febvre y Marc Bloch, a la que contribuyó con valiosos textos; con Maurice Fréchet, matemático, publicó Le calcul des probabilités á la portée de tous (1924), resultado del curso conjunto dado en el Institut Commercial Supérieur de Strasbourg y a su vocación matemática y estadística (no en vano sus estudios filosóficos sobre Leibniz y su tesis complemenatria La teoría del hombre medio de Quetelet); debatía a menudo sobre la conciencia individual y colectiva con el psicólogo Charles Blondel, de la misma forma que sus intercambios eran habituales con otros estudiosos como el jurista Gabriel Le Bras, los filósofos Martial Guérolt y Maurice Pradines o con el geógrafo Georges Lefebvre. Abundan los artículos donde unos y otros cruzan referencias, aunque en este juego de síntesis, encuentros y construcciones recíprocas no escasearon los recelos entre quienes creían representar la quintaesencia intelectual ni ahorraron entre sí rivalidad por prosperar en la carrera académica7. Halbwachs seguía comprometido con el proyecto sociológico durkheimiano, acusado de imperialismo académico por algunas disciplinas que sin embargo aspiraban a construirse sustrayendo muchas de sus aportaciones, forjando al cabo una imagen deformada de su interés ${ }^{8}$. Lo cierto es que la sociología durkheimiana se encontraba bastante debilitada y dispersa, en situación de marginalidad institucional pese a su prestigio intelectual. Esto empujó a los depositarios de su legado a conectar con otras ramas de conocimiento afines, esgrimiendo una voluntad de acercamiento que se revela en parte táctica. Por ejemplo, en la reconstrucción y en la difusión: la dependencia de otras revistas para sus publicaciones es tal que entre 1918-1943 el propio Halbwachs sólo dispone tres de sus treinta y cuatro artículos en revistas de sociología propiamente dicha ${ }^{9}$.

6 H. Berr (1921), “L'Esprit de synthèse dans l'enseignement supérieur. L'Université de Strasbourg”, Revue de synthèses historique, 23.

7 Especialmente por la posibilidad de postularse para un puesto en París (Universidad, Collège de France).

8 Heilbron, (1985, p. 208), en una fórmula retórica reconocible, dice al respecto que "las representaciones dominantes de la sociología [durkheimiana] fueron las representaciones elaboradas en las disciplinas dominantes".

9 Heilbron, 1985, p. 210 


\section{Los durkheimianos, el mecenazgo americano y la reconstrucción de la investigación en Francia.}

El reconocimiento de facto de una "coordinación" interdisciplinar no significaba en absoluto una renuncia a las proverbiales ambiciones de la tradición durkheimiana respecto a la orientación sociológica del conjunto de las ciencias sociales. Pero las condiciones de la investigación y de la enseñanza superior en Francia perfilaban un escenario complejo. A los problemas estructurales -financiación escasa, fragmentación institucional, dispersión disciplinar y facultativa, penuria de recursos (Mazon 1985; Tournès 2007)- se añadía la pérdida de investigadores durante la contienda ${ }^{10}$. Asegurar el porvenir de la sociología durkheimiana fue misión asumida por sus principales depositarios: Marcel Mauss, Celestin Bouglé y Maurice Halbwachs. Y el panorama no era alentador: L'Année sociologique había dejado de editarse; su enseñanza seguía en un plano bastante marginal y apenas eran tres las cátedras ocupadas por los durkheimianos, dispersas y discontinuas.

Esta aspiración se vio en parte habilitada en el clima de reconstrucción de los estudios superiores en Francia a partir de 1920. Un esfuerzo que contó parcialmente con la contribución de la Fundación Rockefeller ${ }^{11}$ dentro de su política de sostén económico y promoción de programas de investigación y formación superior en Europa durante el período de entreguerras ${ }^{12}$. La implicación fue más allá de arbitrar ayudas destinadas a la creación de redes internacionales de investigación y formación (fellowships), becas de movilidad o la construcción de centros científicos integrales (institution buildings). En términos de Tournès (2007) se apuntaba a la "coproducción de una política de investigación". Además de asistencia financiera a algunas universidades, escuelas superiores y centros de investigación, la Fundación se arrogaba un margen discrecional para definir la orientación de las prácticas científicas y los modelos de organización académica. En esta trama se hilvana el viaje de Halbwachs a Chicago.

Respecto a las ciencias sociales, la Fundación pretendía rehuir el canon especulativo asociado a los modos europeos y se decantaba por un modelo de conocimientos científicotécnicos aplicados, una especie de "ingeniería social" bien anclada en la tradición reformista americana. En esta orientación la interdisciplinariedad planeaba con soltura. Sobre dicho

10 La propia escuela durkheimiana había visto desaparecer a muchos de sus miembros: Antoine Bianconi, Robert Hertz, Maxime David, Jean Reynier, R. Gelly, André y Émile Durkheim.

11 Ha sido ampliamente tratado el alcance de su labor filantrópica en los EE.UU., primero de naturaleza caritativa, después vagamente reformista y finalmente, orientada hacia el interés general -siguiendo la "racionalización filantrópica" o método científico del don- (Mazon, 1985; Tournés, 2007). Baste con mencionar para nuestros propósitos el impulso y patrocinio de la Universidad de Chicago (1890) y de institutos de investigación como el Social Science Research Council de Nueva York (1923) y la construcción del Social Science Research Building (1929). Dos fueron las instituciones filantrópicas del imperio Rockefeller, la Laura Spelman Rockefeller Memorial y la Rockfeller Foundation. En 1929 esta absorberá definitivamente a la primera cuya labor se orientaba a la promoción de la investigación y enseñanza superior en ciencias sociales y económicas.

12 A partir de 1920 la Fundación procuró internacionalizar su radio de acción, hecho sobre el cual no puede excluirse una lectura en términos de imperialismo, hegemonía cultural y propagación ideológica de los valores del capitalismo americano (Tournés 2007). La labor filantrópica en Europa se desarrolla preferentemente en Francia, Inglaterra y Alemania (considérese entre otros ejemplos su apoyo a las Facultades de Medicina de Estrasburgo, Lyon, la creación de la Maison Internationale en la CIU de París; el mecenazgo de la London School of Economics y de la Deutsche Hochschule für Politik de Berlin). 
esquema probablemente se habrían sentido más cómodos trabajando con los leplaysianos con una concepción más operativa o aplicada del conocimiento-, pero estando estos distanciados de las instituciones académicas, fueron los durkheimianos Mauss y Bouglé -en el Institut d'Éthnologie y el Centre de Documentation Sociale (CDS) de la École Normale Supérieur respectivamente- los designados como interlocutores de la Fundación Rockefeller.

En 1925 Mauss fue nombrado advisor de la Fundación e invitado en 1926 a visitar universidades y centros de investigación norteamericanos, Chicago entre ellos. Profundamente impresionado por su organización, dinamismo y disponibilidad de medios, Mauss esboza un proyecto de Instituto de Ciencias Sociales (destinado a integrar la VIa Sección de la École Practique d'Hautes Études). Su propósito: un órgano de apoyo a la investigación y formación en ciencias sociales bajo la premisa de su coordinación en campos generales (métodos cualitativos y estadísticos, sociología, geografía humana, historia...). En esta nueva disposición, la sociología debía renunciar a su dimensión especulativa, generalista, para centrarse en investigaciones descriptivas sobre temáticas precisas (Heilbron 1985; Mazon 1985; Tournès 2007). El proyecto de Mauss resultaba tan ambicioso como incierto, y sobre él se cernía la sospecha de incapacidad para llevarlo a cabo (además del perfil socialista). Bouglé, en la cátedra de Economía Social de la Universidad de París y del CDS, con más dotes organizativas, sería el siguiente interlocutor de la Fundación. El mismo acariciaba la idea de un Instituto de Sociología (al modo del Instituto Solvay de Bruselas) donde activar la síntesis positiva de las ciencias. En ese modelo insistirá en la conferencia pronunciada en el Coloquio de Chicago, cuando acudió invitado a la inauguración del Social Science Research Building de la Universidad de Chicago en diciembre de 192913. Aunque ninguno de los proyectos llegó a buen término, en ambos casos se manifiesta la voluntad de encaminar las ciencias sociales hacia un terreno marcado por la investigación empírica, de rigor metodológico y ambición teórica, bajo la tutela de la sociología.

Tal es el contexto de oportunidades y afanes que embarga a los durkheimianos, bloqueados en la universidad, sin reemplazo efectivo, acechados por la pujanza de disciplinas renovadas con mayor presencia institucional y la emergencia de una nueva generación que provocativamente renegaba de sus predicados ${ }^{14}$. En estas circunstancias tiene lugar el desplazamiento de Halbwachs a la Universidad de Chicago, centro bien surtido de la "filantropía" Rockefeller, que también patrocinó buena parte de las encuestas y monografías del Departamento de Sociología. No llegó estrictamente comisionado para una tarea de interlocución mas sí decidido a extraer enseñanzas y relaciones que contribuyeran a la reconstrucción de la sociología empírica francesa. Así, en la misiva de respuesta a E. Faris aceptando su invitación a incorporarse, Halbwachs expresa abiertamente el deseo de

13 C. Bouglé, “The present tendency of the Social Sciences in France”, en Leonard S. White (ed.), The new Social Science, Chicago: Chicago University Press, 1930. Una versión francesa del texto aparece en el primer número de los Annales sociologiques, la revista que retoma el proyecto de l'Année sociologique original, suspendida en 1924.

14 Se trata de la llamada "generación de los 30" formada entre otros por Paul Nizan y Henri Lefebvre, alejada de las formas academicistas anteriores, reivindicativa y provocadora. Vid. Heilbron, 1985. 
“estudiar la organización de su departamento. Tenemos mucho que aprender de ustedes"15. ¿Simple fórmula protocolaria? Al solicitar una rebaja en la dedicación de las clases a impartir y la posibilidad de agrupar los días de clase insiste de nuevo en que "desearía además disponer de un poco de tiempo para estudiar su organización y hacer investigaciones sociológicas entre ustedes"16. Abundando en esta idea, en una carta sin destinatario precisado (Archivos Henri Pieron) Halbwachs afirma haber sido "invitado por la Universidad de Chicago a impartir un curso de Sociología estadística y encargado de una misión del Ministerio de Instrucción Pública" 17. Respecto a lo primero, sabemos que el estadístico es uno de los campos de mayor interés y competencia de Halbwachs, que en 1930 todavía acaricia la cátedra de "Sociología estadística" pretendida por la Universidad de París (que nunca verá la luz) como también había soñado con una "estadística moral" en el College de France. En realidad, los cursos impartidos en Chicago -fijados por E. Faris en su invitación- versaron sobre la "sociología francesa moderna" (el debate entre Tarde y Durkheim) y "El suicidio", tema sobre el cual acababa de publicar su actualización del clásico de Durkheim (Les Causes du suicide, 1930). Respecto a la comisión ministerial, no hay constancia de ninguna; lo cual no obsta para admitir, como ha observado Topalov (2012) que Halbwachs obra como un figurante útil no siempre consciente del juego, inmerso en una trama de intereses cruzados para la educación superior francesa entre los durkheimianos y los agentes de la Fundación Rockefeller, que no termina de cuajar.

Dicho esto, Halbwachs va encaminado asimismo a investigar en ese orden de cuestiones que ocupan buena parte de su itinerario académico: la morfología social y la sociología económica (siempre apoyándose en la estadística), ámbitos de estudio que no se mencionan en la invitación y cuya ausencia es per se ilustrativa de los avatares de su recepción.

\section{La universidad chicaguense: una perspectiva desde la tradición francesa}

Halbwachs enfrenta la experiencia americana con un sobrado bagaje y en una fase de trabajo creativa y prolífica. A sus 53 años estaba versado en ambientes intelectuales de distinto cuño, pero de sus escritos y correspondencia privada con familia, amigos y colegas se desprende la honda impresión que le suscita la organización y la diligencia de la universidad americana, como la propia metrópoli, siempre excesiva. El cuadro es soberbio incluso para quien proviene de la excepción alsaciana. No en vano para esas fechas Chicago era posiblemente la metrópoli más investigada del mundo y contaba con una buena base de datos empíricos básicos reunidos por las secciones de la Universidad de Chicago.

"La Universidad de Chicago fue fundada hace 30 años por Rockefeller, es una verdadera pequeña ciudad en la mayor. Edificios lujosos de arquitectura medieval que

15 Lettre à Faris, 30 abril 1930 (Halbwachs 2012: 85-86). En adelante todas las citas de la correspondencia de Halbwachs a amigos y familiares se extraen de la magnífica edición reunida por Topalov en M. Halbwachs Écrits d'Amérique, 2012.

16 Lettre à Faris (29 de mayo) (Halbwachs 2012, p. 88-89).

17 Halbwachs, 2012, p. 232. La cursiva es nuestra. 
recuerdan los colleges ingleses de Oxford y Cambridge se espacian en medio de vastos jardines, con praderas de césped y magníficas canchas de tenis. Otras están en construcción; los planos se añaden a los planos. No hay semana en que comisiones de profesores y estudiantes no se reúnan para formalizar nuevos proyectos."18

Admira las facilidades y financiación para la investigación, la abundancia de medios, equipos e instrumentos de trabajo reunidos en el Social Science Research Building, que le entusiasma ("un edificio nuevo de cinco plantas, con ascensor, numerosas oficinas, aulas claras y espaciosas y un bello mobiliario"19). Allí se localizan las famosas "máquinas tabuladoras" en las que cifra la esperanza de la sociología estadística y cuyo funcionamiento procura entender enseguida:

"He ido a estudiar el funcionamiento de las máquinas de cálculo. Tienen una docena, incluso más... Cada una cuesta de 10.000 a 20.000 francos. Es extremadamente interesante. He realizado todas las operaciones posibles (...). Es el gran instrumento de las ciencias sociales y está ahí en el núcleo de sus laboratorios." 20

El despliegue de recursos técnicos y de oportunidades para el debate intelectual y/o la investigación concreta, el encuentro con otros investigadores nacionales y extranjeros con los que coincide en el recinto universitario o en entornos asociados (el Quadrange Club, donde se aloja), acentúan la impresión de una universidad dinámica y segura:

"por todas partes del campus (es el nombre que dan a su emplazamiento) han construido nuevas edificaciones. Si por azar entras en uno de esos colegios (colleges) de aspecto inglés se observa que están instalando un museo o acabar un laboratorio." 21

No menos insólito para un profesor habituado a la sobriedad académica francesa es el hecho de que en la Universidad de Chicago profesores y representantes de alumnos debatan sin mayor ceremonia el contenido de los programas de estudio ${ }^{22}$. En esa misma coyuntura advierte, a partir de las informaciones recabadas, la gran trasformación que se cierne en el centro, a tener presente en el horizonte de la reforma universitaria francesa:

"Tratan sus universidades un poco como a los automóviles, es decir, que tras haberlos utilizado un tiempo, cuando perciben que no rinden, no dudan en reparar, transformar e incluso reconstruir a partir de un nuevo modelo. Así es como suprimen la especialización durante los dos primeros años. En cada gran sección habrá para los debutantes un único curso que versará sobre generalidades. A continuación, cinco secciones: ciencias físicas, ciencias de la naturaleza (incluidas las matemáticas), ciencias biológicas, ciencias sociales y humanidades. Los historiadores se sienten divididos: obligados a elegir entre dos secciones,

18 Le Progres 27 de octubre de 1930 (Halbwachs 2012, p. 255).

19 Lettre à Yvonne, 22 sept.-1 octubre de 1930 (Halbwachs 2012, p. 116).

20 Lettre à Yvonne, 30 de octubre (Halbwachs 2012, p. 139).

21 Lettre à sa mère, 9 de octubre de 1930 (Halbwachs 2012, p. 127).

22 Lettre à sa mère, 9 de octubre de 1930 (Halbwachs 2012, p. 126). 
unos quieren vincularse a las humanidades, pero la mayoría se incluiría en las ciencias sociales (¿qué dirían Fevre y Bloch?)”23

Estos y otros aspectos de la vida y organización universitaria chicagüense son bien registrados por Halbwachs, que en la eventualidad de la renovación académica en Francia descubre complacido que todas las disciplinas científicas tienen cabida en sus centros de estudio así como una desenvuelta interdisciplinariedad entre sus aplicaciones -como deseaba claramente Mauss. Sin embargo, respecto a las ciencias sociales y a la sociología en concreto, enseguida muestra ciertas reticencias sobre la idoneidad de la universidad americana: le sorprende la escasez de referencias teóricas ("esperaba encontrar más teóricos" dice en una carta a Henri Pieron el 12 de diciembre) y esa peculiar inclinación hacia lo profesional y a la investigación específica, fundamentada en el trabajo de campo ("en lo vivo"), en la proximidad con los grupos sociales. Esto resulta particularmente llamativo cuando se observan las grandes ciudades "tan diferentes de las nuestras y que ofrecen una bella materia de estudio" 24 . De esa forma se adentra en el examen de la estructura morfológica de Chicago y en el de esa particular escuela de sociología que tiene en la metrópoli su objeto inmediato de investigación, un mundo en pequeño.

\section{Morfología urbana de Chicago}

Las ciudades americanas -de crecimiento explosivo, entre lo espontáneo y lo artificialresultan muy diferentes de las ciudades europeas, de temporalidades pausadas, de trazas históricas yuxtapuestas. También lo son, por supuesto, de las ciudades de Oriente próximo (Estambul, El Cairo, Alejandría...) que Halbwachs cree reencontrar en algunos rincones étnicos de Chicago -como sucede en el mercado judío de Maxwell Street. En su disparidad, la sociedad y las metrópolis estadounidenses le provocan sentimientos contradictorios y no disimula la conmoción que lo embarga ante ellas. Ya en el primer artículo escrito para el diario Le Progres de Lyon ("La llegada", 20 octubre de 1930), confiesa la impresión que le causa Nueva York, el espectáculo de sus gentes y de su arquitectura, "los famosos skycrapers, los rascacielos, de una arquitectura cúbica y paradójica que atrae la mirada como un reclamo y sin embargo no carece de grandeza... Nada de lo que se ha visto se parece a esto y podría figurarse uno haber desembarcado en un planeta nuevo habitado por gigantes que construyen a su medida. Símbolo de la febril actividad de un pueblo al que nada asombra, que se arriesga a todo y se complace en enormes desafíos" (Halbwachs 2012, 252). Otro tanto sucede con Chicago, la metrópoli americana por excelencia, la urbe excesiva, la misma a la que Max Weber se había referido años antes como una "delirante mezcla de pueblos", que a todos deslumbra por su magnitud, dinamismo, por la movilidad de sus habitantes, su orientación hacia el futuro y su disposición pragmática en todas las esferas de la vida. "Todo el pasado y el futuro de América pueden leerse en esta ciudad" escribe en una de sus cartas (20 de noviembre de 1930). Lo extraordinario de esta gran ciudad se manifiesta de entrada

23 Lettre à Yvonne 18 de diciembre (Halbwachs 2012, p. 208).

24 Lettre à H. Pieron, 12 diciembre de 1930, en Halbwachs 2012, p. 236 
en sus aspectos materiales, en su extensión y en su masa, no dominada por la pesantez sino por su potencia.

Contradiciendo a Julian Street -que declaraba que para describir Chicago uno podía emplear todo el diccionario pero jamás las estadísticas ${ }^{25}$ - Halbwachs realiza el abordaje inicial de Chicago en clave de registros, con los datos del volumen poblacional, el ritmo de crecimiento, la densidad y la expansión territorial de la ciudad. La estrategia empleada para dar cuenta de las impresiones e imágenes de la metrópoli es propia del análisis morfológico que viene perfilando desde su integración en el círculo durkheimiano, y en especial en su vertiente urbana ${ }^{26}$. Recordemos que en sus comentarios en "La ville capitaliste d'après Sombart" apuntaba que "la forma de las agrupaciones humanas, su densidad, sus migraciones, su distribución y sus tipos residenciales conforman la materia de una ciencia especial denominada morfología social" (Halbwachs 1905, 744). Y su tesis Les expropriations et le prix des terrains à Paris (1860-1900) (1909) se construyó sobre la sociología económica y las formas de articulación entre el territorio y la población, sobre la relación espaciosociedad. No se trataba sólo de delimitar un objeto de investigación, definido por las formas materiales de la vida social, sino plantear una estrategia de conocimiento acerca de lo social: alcanzar desde el sustrato material "las regiones de la psicología colectiva" que explican su formación. La morfología era así el primer nivel de profundidad de la sociedad, y de este modo, de la explicación sociológica. En palabras de Durkheim (L'Année sociologique 1896/97):

"La vida social descansa sobre un substrato cuyo tamaño y forma está determinado. Este substrato está constituido por la masa de individuos que forman la sociedad, el modo en que están distribuidos sobre el suelo y la naturaleza y configuración de todo tipo de cosas materiales que afectan a las relaciones colectivas. El substrato social varía según la población sea grande o pequeña, y más o menos densa, concentrada en ciudades o dispersa sobre el campo, según cómo las ciudades y las viviendas están construidas, según sea más o menos extensa el área ocupada por la sociedad, y según sean las fronteras que la delimitan y las vías de comunicación que lo surcan. Por otro lado, la naturaleza del substrato directa o indirectamente afecta todos los fenómenos sociales en el mismo sentido en que los fenómenos psicológicos están mediata o inmediatamente relacionados con el estado del cerebro. He aquí, pues, todo un conjunto de problemas en que obviamente está interesada la sociología y que -puesto que se refieren a un solo y mismo objeto- debe ser situado bajo su jurisdicción. A esta ciencia proponemos llamarla morfología social." 27

En obediencia morfológica este planteamiento subyace en el análisis de la estructura urbana de Chicago: determinación del volumen y ritmo de crecimiento demográfico,

25 "Define Chicago: imponente, monstruosa, variopinta, vital, vigorosa, formidable, indómita, intensa, antinatural, aspirante, poderosa, absurda, trascendente -defínela como quieras-, ¡con el diccionario entero! Puedes hacer lo que quieras salvo dispararle estadísticas" J. Street (1914) Abroad at Home: American Ramblings, Observations and Adventures of J. Street, Century, Nueva York p. 139, en A. Pizza y M. Pla, Chicago- Nueva York: Teoría, arte y arquitectura entre los siglos XIX y XX. 2012, p. 7

26 Martínez, E. (ed.) 2008.

27 Durkheim 1897, p. 521. 
localización y desplazamientos territoriales ofreciendo con minuciosidad datos, coordenadas espaciales y referencias temporales para situar el crecimiento en tamaño, velocidad y distribución. Es algo más que afán de inventario dominado por un espíritu de geometría pues no olvida evocar la audacia de los pioneros, la movilidad territorial y social de la población. Y en tanto que Chicago es la más clara expresión de la estructura morfológica metropolitana de los EE.UU. sólo una caracterización rigurosa desde el estudio del sustrato material permitiría una formulación positiva de los aspectos fisiológicos/ funcionales de las ciudades americanas.

"Chicago ocupa, pues, una posición central. No hay ciudad en los Estados Unidos cuyo desarrollo guarde una relación más estrecha con el crecimiento de esta población, con ese movimiento expansivo que la ha llevado no sólo hacia el Oeste sino hacia toda la región intermedia, en particular al Middlewest, tierra de pioneros y colonos (...) desde el lago Michigan hasta el Mississippi."28

"Chicago, expérience ethnique" constituye un delicado estudio basado en fuentes diversas. La tónica del trabajo de gabinete, paciente, se impone en su quehacer: lectura analítica, recolección y explotación de estadísticas y empleo de fuentes y datos secundarios de todo tipo. Junto a ello, sin llegar a asimilarse a un trabajo etnográfico de campo, Halbwachs recurre a paseos por los entornos de los que escribe, al modo en que lo hacía en París. Es una forma de tomar contacto y realizar observaciones in situ que aporta matices y enriquece sus juicios. También se sirve de las referencias que le proporcionan interlocutores valiosos, principalmente Ogburn, que es quien le acompaña y guía por el entramado de la ciudad y del mundo universitario de Chicago. Es Ogburn quien le refiere a grandes rasgos la conformación de la sociología americana y filtra su apreciación. En realidad, como veremos, son escasos y breves los acercamientos a Burgess, Park y McKenzie cuyas obras -y las de esa "particular escuela de sociología"- emplea sin embargo para esclarecer la estructura urbana y la composición social de Chicago, a todas luces extraordinaria.

El procedimiento estadístico, capital en su concepción del progreso de la sociología científica, le permite apoyarse en el método comparativo, que emplea una y otra vez para dar cuenta de la evolución urbana de Chicago. Tablas comparadas construidas sobre fuentes primarias y secundarias, con números índices con los que cotejar la evolución y las distintas situaciones de los grupos sociales y urbanos. Primero con Nueva York, la metrópoli de referencia americana, muy del Este; pero inmediatamente después con Europa, sobre todo París, a la que ha dedicado varios estudios en diferentes momentos. Esta operación le permite de un lado realzar los contrastes (las proporciones y el ritmo) y de otro ratificar la relación existente entre la presión demográfica y el ensanche de la ciudad, una tesis central establecida en sus trabajos pioneros de morfología urbana.

La exposición no se detiene en el aspecto demográfico; también acomete la dimensión territorial, pues el espacio cobra plena relevancia en la interpretación morfológica. Mostrar la extensión de Chicago habilita enteramente el uso de las nociones de densidad material y dinámica expuestas por Durkheim en Las reglas del método sociológico (1895), que enlazan 
las manifestaciones morfológicas e ideacionales de la vida colectiva (en particular en la concepción del milieu).

Por lo mismo, Halbwachs se recrea en la imagen de un Chicago punto nodal del sistema ferroviario americano, cuya descripción retoma en sus artículos de prensa para Le Progres de Lyon y en la correspondencia privada: "Si tomáramos la longitud de las vías férreas de Suiza o Bélgica -expresa maravillado-, veríamos que no son tan extensas como las de esta ciudad. En cuanto a la rapidez, se precisa más de media hora para salir. Alrededor de uno no se ven sino líneas y líneas de raíles, vías muertas, vías de servicio multiplicadas, talleres y depósitos inmensos, etc. y se imagina uno que no existe nada más." (Halbwachs [1932] 2008, 204). Un cuadro que remite sin duda a la definición canónica de la morfología social, donde esbozaba el valor de los dispositivos tecnológicos y de los medios y vías de comunicación para salvar las distancias entre los individuos y grupos sociales (densidad dinámica y cohesión social).

El autor insiste en la magnitud de esa estructura física, que se aprecia asimismo en el número, tamaño, extensión y longitud de las calles; en la presencia de instalaciones industriales por doquier; espacios vacíos, y un patrón muy polarizado entre un centro urbano activo, vertical y denso frente a una periferia dilatada, dominada por viviendas unifamiliares construidas en madera. Se trata de una disposición en damero (a partir de la parcela cuadrada de media milla) a la que corresponde una tipología edificatoria típica según el modelo del balloon frame, estandarizado y poco refinado. Una formación urbana completamente distinta a las que uno encontraría en las ciudades europeas (de nuevo París como referencia de contraste), crecidas poco a poco, de adiciones lentas e integradas, y continuidad de espacios construidos y viarios... Todo ello, junto a una morfología social (demográfica) característica, apunta a una fisiología particular (funciones, vida social y disposiciones diferentes, y viceversa) de la vida urbana americana. Trenes, tranvías, ascensores, electricidad, elevated raiways, automóviles privados: el crecimiento urbano está asociado también al desarrollo tecnológico, a la potencia industrial y comercial de la ciudad. Las descripciones tienen en general una fuerte carga visual, procurando transmitir la experiencia de la sociedad-masa, el ballet mecánico que se antoja la metrópoli americana, la afirmación voluntariosa, la aglomeración y la velocidad, cual figurante de una sinfonía urbana. De hecho, así relata en una de sus cartas las sensaciones al moverse por el Loop:

“Tomé el tren a las 11h.: vagones de una longitud impresionante, donde todo el mundo va sentado... Desembarcado en Randolph Street, que es la estación terminal. Uno se encuentra en Nueva York de nuevo: el mismo movimiento, más intenso aún. Y la masa es más pintoresca. En esta región entre el lago Michigan y el río Chicago se acumulan los rascacielos, cines, restaurantes, tiendas y comercios suntuosos. Pero la cabeza me daba vueltas. Entré en una gran cafetería, es increíble. Me he dejado atrapar en una fila de gente a la que maquinalmente he imitado (como el cerdo en el matadero). He tomado una bandeja de metal, un plato ..."29 


\section{Chicago, laboratorio social y sociológico}

Una vez perfilada la metrópoli de acuerdo con sus características demográficas y territoriales, Halbwachs está en condiciones de abordar su estructura general, las formas de vida colectiva, sus representaciones y la diferenciación interna que presenta la urbe. La mayor parte de las referencias que emplea acerca de la distribución en el espacio de actividades y grupos sociales que otorgan a la metrópoli chicagüense esa atmósfera particular procede de las obras de los sociólogos de Chicago, en concreto el libro de Park y Burgess, The City. Aquí reside el núcleo de la recepción de los trabajos de esa "particular escuela de sociología" decididamente original y cuya constitución y forma de trabajar guarda una conexión directa con la realidad metropolitana. Chicago es un laboratorio social y sede de un laboratorio sociológico ${ }^{30}$ :

"La existencia en la Universidad de Chicago de una original escuela de sociología no deja de guardar relación con el hecho de que esos observadores no tienen que buscar muy lejos un objeto de estudio. Ante sus ojos se despliegan (...) nuevas fases de una evolución urbana sin parangón. (...) Todo ello en una aglomeración enorme, con múltiples diferenciaciones según raza, nacionalidad, profesión y nivel social, también según los estilos de vida y las características morales, de tal modo que los medios sociales más diversos se yuxtaponen y se enfrentan a veces sin transición. (...); grupos desintegrados, grupos en formación, vida colectiva dispersada, concentrada, suspendida y ralentizada, agitada y discordante, de tal modo que las características más anormales aparecen ahí con toda claridad (criminalidad juvenil, vagabundeo) o bajo formas que no es posible encontrar en ninguna otra parte." 31

Esta es la primera alusión en la sociología francesa a la escuela de Chicago, mención que ha autorizado a algunos a tomarlo como engarce entre ambas escuelas de pensamiento. En realidad, en las páginas consagradas por Halbwachs a presentarla se pone de manifiesto una crítica cursada en términos algo informales, sin atender realmente a sus presupuestos teóricos ni los métodos de trabajo. Son juicios enunciados un poco al bies, mientras toma sus obras como guía para adentrarse en la comprensión de esa estructura socio-morfológica particular. Es su investigación sobre Chicago, no la de ellos, lo que cuenta. Junto a sus observaciones de primera mano -tomadas en paseos e incursiones en algunas áreas de la ciudad- Halbwachs analiza paralelamente textos y contexto, aprovechando las explicaciones

30 Albion Small en 1896 y R. Park en 1929 ("The City as Social Laboratory") se refieren a la ciudad como un laboratorio social, escenario donde una variedad de tipos sociales y situaciones se prestaban inmediatamente al estudio científico. La analogía clínica fue manejada por varias universidades americanas: Leclerc muestra que la Universidad de Columbia presentaba Nueva York como el laboratorio natural de la ciencia social; y en 1901 el Catálogo de la Universidad de Chicago se refería a la ciudad como "uno de los laboratorios sociales más completos del mundo (...) Ninguna ciudad del mundo presenta mayor variedad de problemas sociales típicos que Chicago. Las asociaciones caritativas así como las organizaciones religiosas de la ciudad proporcionan a los estudiantes de la Universidad una formación y un empleo" (vid. Grafmeyer \& Joseph 2004, p. 7). Sin embargo y Halbwachs pasa por alto esta apreciación- en el planteamiento de Park el símil clínico aboga por evitar que el análisis de la sociedad se pretenda científico y moral a la vez. A diferencia de los sociólogos de la generación anterior, ligados al reformismo, Park diferencia entre el discurso normativo y el descriptivo, de ahí la analogía biologicista.

31 Halbwachs [1932] 2008, p. 207. 
ofrecidas por los profesores que lo acompañan y acogen en el departamento, siendo Ogburn su más preciado cicerone. No obstante, Ogburn era un sociólogo formado en la Universidad de Columbia, de orientación cuantitativista y redactor-jefe del Journal of American Statistical Association (1920-1926). Compartía con Halbwachs esa disposición hacia la investigación social amparada en la estadística ${ }^{32}$ y la forma liviana como le presentó la sociología chicaguense, a decir de Topalov (2012) pudo condicionar la recepción superficial que hizo Halbwachs de sus trabajos:

"Hacen estudios extraordinarios en Chicago. Ogburn me ha contado esta mañana lo que han encontrado aquí: en las "casas de citas", la madame era antes en general una americana, y las chicas, judías. Después la madame era judía y las chicas eran negras. Después la negra pasaba a ser la madame y las chicas eran entonces mexicanas (...). [Y le dibuja un esquema de círculos concéntricos -de Burgess- sobre la edad y distribución de los niños criminales, descendiendo la edad según su lejanía al centro, una lectura anecdótica y burlesca de la ecología humana] "Estos sociólogos americanos son más divertidos que Mark Twain. Es preciso que vaya a ver a Parker [sic] y Burgess que llevan a cabo este tipo de estudios urbanos sobre una gran escala." 33

Halbwachs parece, pues, desconocer los trabajos urbanos del Departamento en que se integra, así como ignorar todo acerca de Park y Burgess. Pero lector impenitente y curioso, se sumerge en las monografías de la sociología de Chicago y con dichas referencias construye el texto citado ${ }^{34}$. El lector francés es conducido a partir de ahí por las sucesivas zonas concéntricas que delimitan las fases de crecimiento y los contenidos sociales y funcionales de la metrópoli (según el diagrama de Burgess, que reproduce). Un paseo desde el loop central hasta la franja de viviendas unifamiliares y espaciosa de la periferia. Se adentra por la Hobohemia, las zonas de transición y áreas de vicio, la Bucktown, etc., nombres exóticos y evocadores. El modelo viene presidido por dos procesos ecológicos -centralizacióndescentralización; e invasión-sucesión - cuya formulación y anclaje teórico Halbwachs pasa por alto, aunque lo retenga en su desarrollo explicativo, interesado más en el examen morfológico de procesos sociales, demográficos y urbanos. No obstante, advierte que la disposición territorial resultante es completamente extraña a la forma urbana de las ciudades europeas debido a la intensidad y rapidez con que se realiza su crecimiento, así como a la amalgama de grupos sociales y étnicos en su recinto. Las urbes europeas y por supuesto París no poseen esa abundancia de grupos étnicos en su interior, formándolas, recorriéndolas y recreándolas. Otro elemento característico de su morfología es la ausencia

32 Ogburn y Halbwachs comparten una misma orientación científica disciplinar, alejada de la especulación. Además de apoyarse en sus trabajos para la elaboración de su obra Classes Ouvriéres (1933), Halbwachs y Ogburn mantienen una estrecha relación de amistad que perdura después. A una misiva de él en febrero de 1945 responde Yvonne Halbwachs para comunicarle la muerte de Maurice en el campo de Buchenwald, carta publicada en el vol. 51 del American Journal of Sociology (1946, p. 326-327).

33 Halbwachs 2012, p. 120-122.

34 Además de The City (1925) Halbwachs maneja las obras del Illinois Crime Survey, 1929, de John Landesco; Harvey W. Zorbaugh, The Gold Coast and the Slum (1929); Louis Wirth, The Ghetto, (1928); Frederic M. Thrasher, The Gang (1927); Clifford R. Shaw, Delinquency Areas (1927) y del mismo autor, The Jack-Roller (1930); también el trabajo de Nels Anderson, The Hobo (1923). 
de sedimentos históricos que condicionen su plano, especialmente llamativo en el centro urbano. No hay ninguna referencia al gran incendio de 1871, que marca el devenir moderno de la ciudad, pero puede decirse que Halbwachs capta bien la trascendencia del "designio" urbano de Chicago: el centro es en efecto menos representativo del pasado como de lo que está por venir. Cual configuraciones isomórficas: la "disposición material” expresa la "disposición anímica" de la civilización americana.

La segunda banda de crecimiento, denominada "área de transición" por los ecólogos de Chicago, posee un registro específico. Se trata de un espacio de tránsito, animado y desorganizado, que no obstante mantiene áreas sociales consolidadas. Halbwachs se orienta en él a partir de las descripciones detalladas que le proporciona la lectura de los trabajos chicagüenses. Con estas referencias traslada al lector francés la impresión de algunas de estas demarcaciones típicas que definen lo que en su día era residencia de los independent wage earners y poco a poco se convirtió en un lugar de pobreza, deterioro físico y moral, violencia y abandono. Allí los slums, acá los asentamientos de inmigrantes, las misiones y los settlements (como Hull House) que se avecinan con el "barrio latino", las colonias de artistas y los centros radicales, las pensiones baratas de población nómada. Dos áreas reclaman su atención: el "cinturón negro" (black welt) y el gueto judío. Como muchos otros sectores de la ciudad ambos son resultado de procesos migratorios de gran alcance y resultado de las tensiones étnicas. Pero en este caso, en una ciudad construida por aportes migratorios venidos de todos los rincones del mundo y orientados hacia una "americanización"-que prefigura su conformismo-, el caso de los judíos y de los negros muestra las resistencias e impedimentos culturales a fundirse en un cuerpo único.

"El lunes fui a ver los viejos barrios habitados de inmigrantes: en el quinto pino. He caminado bastante tiempo, he atravesado un parque inmenso, después el 'black belt', 'el cinturón negro', el barrio de los negros que se extiende del centro hacia el sur, decenas de kilómetros. (...) [también visita el Ghetto]. He pasado una hora en un viejo mercado verdaderamente extraordinario, donde se hablan todas las lenguas de Europa, pero sobre todo el judeo-alemán."35

En la descripción de estos fragmentos metropolitanos Halbwachs introduce sus propios esquemas interpretativos, dando más peso a los fenómenos observados. Así obra respecto al proceso de asentamiento gradual de la población negra a lo largo de Drexel Avenue y la constitución del black belt: "Desde que los norteamericanos [blancos] se ven en contacto con los negros de un modo más estrecho y frecuente que antes, las costumbres restablecen las barreras suprimidas por las leyes e intentan mantenerlos a cierta distancia, ya que no han podido privarles del derecho a alquilar o comprar viviendas. Se produce entonces un fenómeno muy curioso: desde el momento en que los negros han logrado poner el pie en alguna casa (tras realizar negociaciones en secreto con uno o varios propietarios entre quienes el deseo de ganancia prevalece sobre los prejuicios raciales), entonces, en toda la calle, de una longitud de 4 o 5 kilómetros, a veces de 7 u 8 kilómetros, las casas comienzan a vaciarse, los apartamentos quedan vacantes y los blancos van desapareciendo, cediendo el

35 Halbwachs 2012, p. 161-62. 
sitio a los recién llegados. De este modo se explica la formación del black belt." (Halbwachs [1932] 2008, 213) La ecología urbana lo explicaría como un proceso de sucesión (noción que Halbwachs omite). En el esquema halbwachsiano el asunto remite, en otro orden de cuestiones, a la constitución del "valor de opinión" del suelo (y la vivienda) que había mostrado en la explicación del crecimiento y la especulación urbana de París (1909). Esa especie de interdicción de contacto social conlleva repercusiones inmediatas sobre la formación de los precios del suelo y sus derivados inmobiliarios: un valor de opinión del suelo diferenciado según las características del entorno, la situación y los contenidos sociales del mismo. Dicha formulación rompía con las explicaciones del modelo tautológico de ofertademanda, y hacía sin duda del suelo una mercancía singular porque sus variaciones de precio obedecían a necesidades colectivas y a representaciones sociales que iban más allá del juego simple de oferta-demanda. En este caso actúan las representaciones sociales (estigmas) sobre el grupo étnico que se traducen en conductas de evitación. Así, el factor situación no remite a las coordenadas del espacio geográfico (pues eran viviendas de un sector antes blanco y cerca del entorno universitario), sino a la posición en el espacio social de los grupos e individuos, esto es, a una estructura social desigual y jerarquizada social y étnicamente. Si las mejoras públicas emprendidas en el entorno material pueden marcar la valorización diferencial de determinados lugares, introduciendo un plus en la formación del precio, aquí se observa cómo el desprecio (social) genera una depreciación de los valores económicos del suelo.

En este contexto, la representación colectiva materializada en un componente del precio queda articulada por la dimensión étnica, que se impone, y bajo ese prisma, el del problema de la segregación de grupos sociales y étnicos (el ghetto judío, las colonias étnicas), es como analiza en general la realidad urbana americana. El propio título lo atestigua: una experiencia étnica. A este asunto, el de las relaciones y distribución de los grupos migrantes, dedicará los dos siguientes apartados del texto, y de nuevo sobre un asiento estadístico, sin atender las investigaciones sobre las relaciones étnicas de Park, cuya trayectoria y reconocimiento al respecto quedaban fuera de toda duda. En este análisis Halbwachs no pierde de vista el trasfondo de la desigualdad de clase, un aspecto este que permanece fuera del foco ecológico.

Hay que destacar que el estudio de la estructura morfológica y el análisis del comportamiento y distribución socio-espacial de los diferentes grupos migratorios proporciona al autor la posibilidad de proseguir en una dirección analítica que había ido cobrando forma en Estrasburgo: la sociología de la memoria, por la que será ampliamente reconocido. En 1925 había publicado la primera de sus obras sobre el tema: Los marcos sociales de la memoria -donde ya sitúa el espacio como un marco de localización y resorte de los recuerdos-. Como comenta en una de sus cartas a propósito de las líneas de desarrollo de la sociología americana, esta obra es conocida y apreciada allí en el ámbito de la "sociología psicológica" (vid. infra nota 33). Halbwachs se siente impresionado ante la marcada orientación hacia el porvenir inmediato y el pragmatismo característico de la cultura estadounidense. ¿De dónde procede tal disposición? Lo cierto es que la tendencia a fundirse 
entre estas sucesivas oleadas de inmigrantes los lleva a olvidar al cabo del tiempo sus orígenes y parecen liberarse de anclajes identitarios y territoriales pretéritos.

"Una población sin relación con la nuestra, vigorosa, feliz de vivir, con hábitos bien regulados y mucha libertad con muchas convenciones (...) hablan sin prisa, pero se levantan y van a sus asuntos o distracciones con la regularidad de un péndulo. No sospechan que hay una Europa con tradiciones que nos son tan queridas. (...) Es un mundo que ignora al otro o que lo ha olvidado. Algunos estudiantes me dicen que no recuerdan de qué país proceden sus padres. Todo eso se funde, se difumina, se borra en el intervalo de una decena de años. Con eso, una movilidad extrema." 36

"Temperamento de pioneros, constructores, desbrozadores que van siempre adelante, en el tiempo y en el espacio, y que jamás se vuelven. Siempre organizando, modificando y perfeccionado algo" 37.

Y más adelante, prosigue su ambivalencia:

"Creo decididamente que prefiero el viejo mundo al nuevo. No obstante, hay aspectos de la vida americana que me encantan e incluso me entusiasman (...). No puedo decir exactamente lo que es. Un aire más ligero (...) los espacios, las posibilidades infinitas, algo más rico y más libre. La ligereza respecto a todo el fardo de tradiciones. Y sin embargo toda Europa, todo el pasado, todas nuestras razas y sangres fundidas y refundidas en extraños mestizajes... Siento que sería feliz de ser americano si me fuera posible olvidar Europa. Quizá sea el olvido, el olvido sin pesar, el olvido definitivo lo que otorga a este pueblo su juventud." 38

Las pesquisas sobre los enclaves migratorios llevan al francés a visitar Hull House. Parece casi una obligación entre los intelectuales europeos de paso por la ciudad, tal es la cantidad de ellos que se detienen de un modo u otro en el famoso settlement de Halsted Street, fundado por Jane Addams (entre otros y en varias ocasiones Patrick Geddes, otro referente de la sociología urbana europea). Siendo una de las instituciones más célebres del reformismo social americano, del trabajo con los inmigrantes, no es sorprendente que Halbwachs dirija sus pasos hacia el enclave: en su época de estudiante había formado parte del Comité de alumnos de la ENS de la Societé de Visiteurs, una organización orientada a la asistencia social desde los postulados de la filantropía científica. Pero en una perspectiva más amplia, en Hull House tendrá la oportunidad de topar con la "sociología aplicada" -cercana a la acción social y a los planteamientos reformistas- de la que le había hablado Ogburn en su historia rápida de la tradición americana:

"Ayer, entre mis dos cursos, tuve una larga conversación con Ogburn, que me contó la historia de la sociología americana. Han enterrado deliberadamente la generación que les precedió, los Giddins, Small, etc. (...) Ahora hay cuatro movimientos: la sociología de la cultura (Mauss no pudo comprender qué era y sin embargo sabía bien inglés). La sociología

36 Lettre à sa mère 9 de octubre de 1930 (Halbwachs 2012, p. 126)

37 Ibídem.

38 Lettre à sa mère 20 de noviembre de 1930 (Halbwachs 2012, p. 178) 
cuantitativa (se trata de Ogburn). La sociología psicológica (mi libro sobre la memoria es al parecer muy apreciado en este grupo). Y por último, la sociología práctica. Se trata de Park y Burgess, los jóvenes delincuentes, los medios sociales desorganizados de las grandes ciudades, el Hobo (nunca he podido comprender qué es: un nombre de salvaje, creo). Pero le añaden "hemia" a menudo, en un juego de palabras: hobohemia, los bohemios, los desclasados. Ya ves que es divertido." 39

\section{Recepción marginal y crítica de la escuela de ecología humana de Chicago}

"Divertido". Ese epíteto y otros similares ciñen mayoritariamente el juicio que Halbwachs reserva en sus cartas privadas a la sociología urbana de Chicago ("las cosas de Park y Burgess"), dictamen que hacía extensible incluso al trabajo de los Lynd ("estos días he leído un estudio titulado Middletown, por Lynd, que es sociología ocurrente a menudo, aunque minuciosa y animada" ${ }^{40}$ ). Es llamativo el contraste entre la descripción rigurosa y vívida que hace de Chicago siguiendo el itinerario de los trabajos de los sociólogos chicagüenses y el desafecto hacia sus hallazgos y planteamientos analíticos.

En lo relativo a los intercambios intelectuales con Park y Burgess estos son escasos y ciertamente superficiales con el primero. En la correspondencia privada se desvelan las dificultades para su entendimiento, desde su timidez, sus apuros con el idioma y la distancia cultural entre el mundo académico y social francés, de un lado, y el americano, de otro, un mundo este que lo desorienta de diferentes maneras. De sus primeros contactos en el Quadrange Club queda esta descripción de Park a modo casi caricaturesco (lo llega a identificar con el Teufelsdröck de Sartor Resartus):

“... me disponía a comer solo cuando un sociólogo llamado Park ha venido a sentarse en mi mesa. Este Park es un tipo que debe rondar los sesenta, de fisonomía desabrida, pero que no carece de saber. Tiene aspecto de filósofo alemán. Por lo demás pasó cuatro años en Estrasburgo y fue alumno de Windelbad (...). Se dedica a la sociología urbana. Cuando subí a mi habitación ya no podía más." 41

Se refiere a Park y Burgess como dos investigadores muy diferentes pero complementarios que representan la "sociología urbana". A ellos achaca el carácter pintoresco, ágil y singular de la sociología de Chicago precisada en las monografías sobre el ghetto, los gangs, los slums, las "áreas deterioradas", etc. "La conversación era un poco dura con el segundo [Park], que posee un terrible acento nasal. Comprendía mejor al primero [Burgess]. Me han prometido llevarme a pasear por los slums, el barrio negro, etc. He comenzado la lectura de un libro muy curioso sobre esta ciudad" (Lettre à sa mère 9 de octubre). Se trata de The City (1915), obra clave del programa teórico-práctico de Park y

39 Lettre à Yvonne 5 de diciembre de 1930 (Halbwachs 2012, p. 195)

40 Lettre à Yvonne 19 de octubre de 1930. (Halbwachs 2012, p. 145).

41 Lettre à Yvonne 15 de noviembre de 1930 (Halbwachs 2012, p. 172) 
Burgess a quienes reconoce ese esfuerzo y su valía intelectual para definir una dirección particular de las investigaciones sociológicas.

"Los dos inspiradores de esos trabajos sobre la vida urbana, Robert E. Park y Ernest W. Burgess, resultan en verdad muy diferentes. El primero estudió filosofía en Alemania y se dedicó durante algún tiempo al periodismo. En la obra de la que vamos a hablar, escribió una "Historia natural de los periódicos". Se trata de una fuerte personalidad intelectual: de él provienen las ideas, las sugerencias y los marcos de clasificación que deben guiar a los investigadores. El segundo, Burgess, muy anglosajón de espíritu y temperamento, no disocia en su pensamiento el aspecto teórico del interés práctico de las investigaciones que acomete. Es él quien redactó la conclusión del voluminoso Illinois Crime Survey (1.108 páginas en 8ª , 1929), obra de la Illinois Association for Criminal Justice. Recientemente viajó a la Rusia soviética en la que pasó cerca de un año estudiando la delincuencia juvenil. Estos dos académicos se complementan, y era de esperar que de su colaboración surgiera un libro atractivo en muchos aspectos. Es la impresión que se tiene cuando se le echa un vistazo al libro The City..." 42

Nombra explícitamente los dos capítulos principales: "La ciudad. Sugerencias para la investigación del comportamiento humano en el medio urbano", de Robert E. Park, y "Crecimiento y desarrollo urbano. Introducción a un proyecto de investigación", de Ernest W. Burgess. Pero los términos en que se expresa Halbwachs son algo displicentes: los considera carentes de tradición intelectual y fundamento teórico. The City es juzgado como un ensayo, algo así como "un bosquejo necesariamente imperfecto todavía. Como este tipo de trabajo es tan difícil, exige un concurso de cualidades tan diversas, y está tan enteramente desprovisto del apoyo que podría ofrecerle una tradición de investigación y de análisis científico -a propósito de un objeto de estudio que acaba de ser descubierto-, conviene ser, pues, más curioso que crítico, al menos por el momento" (Halbwachs [1932] 2008, 209). Aunque se apoye en muchas de las monografías de la escuela para su artículo, enseguida muestra las limitaciones de este tipo de trabajos, que considera "libros descriptivos más que científicos, desiguales y a veces decepcionantes" (Halbwachs 2008, 208). Les otorga un valor pintoresco, que los hace atractivos a primera vista pero los sitúa fuera del rigor de la ciencia positiva; literatura naturalista en cierto sentido, bocetos obtenidos desde la cercanía a los grupos sociales y fenómenos estudiados, en un entorno efervescente y vertiginoso. Lo cual no deja de ser irónico sabiendo que The City -basado en la preparación del curso The Survey con que inició Park sus clases en Chicago- puede interpretarse a su vez como una ofensiva formal hacia los planteamientos metodológicos del social survey movement, al que Park concedía un estatuto precientífico.

Una actitud semejante manifiesta al reseñar los procedimientos insólitos de R. Mckenzie en el empleo de la cartografía ecológica típica:

"McKenzie estaba ocupado en clavar chinchetas de colores variados en un mapa de los EE.UU. Tantas chinchetas como condados, iy había más de 1000 condados! Todo con el fin de "visualizar" los resultados del último censo. (...) Creo que la idea que tienen de la ciencia se 
les ha subido a la cabeza. Parecían un poco embriagados. No he tenido ninguna vergüenza en simular una admiración ilimitada." 43

J.C. Marcel (1999) entiende que la experiencia americana de Halbwachs está atravesada por la ambivalencia, entre la consideración y el recelo. Admira y a la vez rehúye esa cercanía de los investigadores americanos con la efervescencia social de la ciudad; confiesa que la escuela sociológica de Chicago y los residentes de los settlements (la sociología práctica en definitiva) realizan un esfuerzo notable para delinear los principales aspectos de una ciudad donde múltiples nacionalidades y clases fermentan juntos, donde son observables combinaciones y reacciones de química social extraordinarias. Pero dicho esto, se lamenta de que "parecen ignorar totalmente nuestras teorías. A este respecto se encuentran en la misma situación que estaban los exploradores y los misioneros frente a Durkheim" (Halbwachs 2012, 207). El símil de los investigadores cual exploradores y aventureros que descienden y avanzan hasta las galerías más profundas de los misterios es del todo franco, pues la correspondencia de Halbwachs se recreaba en la imagen de un Chicago exótico lleno de atmosferas inquietantes (Little Sicily, slums, ghetto, la hobohemia, los asentamientos ilegales o jungles), ambientes urbanos donde la vida social se presentaba bajo las formas más azarosas e inestables, los sectores predilectos de los gangs, las taxi-dancer, jack-rollers, etc. Pero el fondo de su juicio apunta a una caracterización más severa: un designio pre-científico.

La rigidez del academicismo francés pesa en la disposición hacia los planteamientos chicagüenses, llevándolo a una lectura muy parcial y liviana de esas obras, sin reparar en aspectos clave de su propuesta. Primero, por la precipitación con que juzga la supuesta carencia de fundamentos teóricos, que en verdad no escasean -lo que falta son los suyos; por lo demás durante su estancia rehúsa el debate teórico para centrarse en las cuestiones técnicas y de organización. Segundo, por el rechazo a los procedimientos etnográficos, que le son ajenos y chocantes. Es evidente que The City se concibe como un programa de investigación sobre la ciudad a la manera de líneas de exploración e interpretación, un plan de trabajo que se iría componiendo en posteriores monografías del equipo, conformando la tradición analítica que conocemos como ecología urbana. Está muy lejos, sin embargo, de ser un simple esbozo sin fundamento teórico ni profundidad analítica. Halbwachs es incapaz de apreciar en los planos epistemológico, teórico y metodológico de The City la combinación del pragmatismo americano con los desarrollos teóricos plurales y los cauces múltiples de investigación del modelo ecológico. Es cierto que Park tiende a la conceptualización difusa y construcciones algo indeterminadas pero este punto ni siquiera es contemplado en el reproche halbwaschiano; tampoco el esfuerzo de sistematización y explicación de los procesos de la naturaleza humana, atento a las regularidades observadas y a su especialización, en el novedoso esquema ecológico; o su aportación al estudio de la

43 Lettre à Yvonne 6 de diciembre de 1980 (Halbwachs 2012, p. 196). Por otra parte, presenta a McKenzie como ocupado en la "sociología urbana" e interesado en sus estudios sobre París. Es la única manifestación explícita de que alguien del círculo chicagüense muestre un interés abierto por los trabajos urbanos de Halbwachs (y esa carta a su hijo Francis solicitándole tres ejemplares de su trabajo La population et les traces de voies à Paris) 
interacción y la comunicación social. O su contribución notable al estudio de los problemas raciales, que Halbwachs ignora por completo en su análisis sobre los grupos étnicos de Chicago. En otro orden de cuestiones, en "La sociologie en Allemagne et aux États-Unis" (1932), al comparar ambas tradiciones analíticas, el francés insistirá en la predisposición americana al empirismo sin ascendencia teórica (frente a la propensión germana a permanecer en el universo especulativo). No es necesario recalcar las credenciales académicas de Park -formado con Dewey, Santayana, James, Wildeband, Simmel y otros- ni sus referencias teóricas, que fluyen en la célebre Biblia verde, el manual de Sociología editado junto a Burgess del que Halbwachs no da indicación alguna y donde habría encontrado correspondencias teóricas abundantes. Incluidas las del propio Durkheim, a quien, de hecho, Park reclama en 1925 como una de sus fuentes principales en la construcción de la perspectiva ecológica, que asemeja explícitamente con la morfología social

“Dentro de los límites de toda área natural, la distribución de la población tiende a asumir un modelo definido y típico. Cada grupo social muestra una configuración más o menos definida de sus componentes individuales. La forma que adopta esta configuración, en otros términos, la posición de los individuos con respecto a los otros en la comunidad constituye (...) lo que Durkheim y su escuela llaman el aspecto morfológico de la sociedad." 44

Park es todavía más explícito en una reseña del American Journal of Sociology cuando habla de "las relaciones entre la geografía humana y la ecología humana, o la morfología social, como Durkheim la denominaba..."45. Así que no deja de sorprender que Halbwachs pase por alto el debate respecto a las convergencias y divergencias entre la perspectiva ecológica y la morfológica que, a tenor de la exposición parkiana, los sociólogos de Chicago sí parecen apreciar sin complejos de ningún tipo. Nociones bien presentes en la producción chicagüense como la división del trabajo, la competencia, la densidad o la introducción del espacio como una dimensión analítica -más allá de lo que podría entenderse como mera superficie de registro- forman parte también del arsenal crítico de la morfología social desde los primeros textos canónicos. Por lo mismo tampoco considera la analogía existente entre el materialismo morfológico primitivo (con el estudio del sustrato material de la sociedad) y la distinción ecológica entre una infraestructura biótica (material) sobre la que se erige el orden moral, y el tránsito de lo comunitario a lo societario. Y eso sin cuestionar la autonomía reconocida a las representaciones sociales -entre lo durkheimianos- o la especificidad propia de los estados de ánimo -como enfrenta Park la ciudad, yendo más allá del fundamento material. Precisamente sobre estas cuestiones la neo-ecología americana de los años 50-60 apelaría al vínculo entre ambas corrientes analíticas.

Las exposiciones de Marcel (1999), Topalov (2012) y Chapoulie (2013) apuntan al racionalismo obstinado del francés y a sus divergencias metodológicas como el origen de la desconfianza y el alejamiento ante los postulados de Chicago, especialmente a sus aportaciones etnográficas. Cierto que Halbwachs estimaba la habilidad para extraer

44 "The Urban Community as a Spatial Pattern and a Moral Order" en The Urban Communities (1926) p. 3-18, editado por E. W. Burgess. Con este último título aparece en Human Communities (The City and Human Ecology), p. 165-177.

45 Park 1926, p. 486. En Boudes (2011, p. 210). 
información relevante del contacto directo con los grupos sociales, pero los modos etnográficos, por resueltos y vivaces que fueran, escapaban del rigor exigible del conocimiento positivo. De ahí que Halbwachs emprenda el estudio de la "experiencia étnica de Chicago" en términos de operaciones y registros estadísticos, la mejor manera de evitar los riesgos del exotismo y de las apariencias para adentrase en la estructura social de esa y cualquier otra ciudad.

Halbwachs ve en la estadística la herramienta más preciada de observación y de experimentación en ciencias sociales ${ }^{46}$. Por supuesto, conducir la sociología hacia el terreno de la cuantificación no es una concesión grosera a la matematización abstracta: la lógica sociológica ha de ponderar la razón estadística, reconociendo las regularidades sociales frente al desarreglo de los casos singulares.

"El estadístico es el método más positivo que puede aplicarse en sociología, pues nos pone en relación con los números. Estos, es decir, el aspecto cuantitativo de los objetos son un dato que se nos impone desde fuera. (...) En Sociología, donde los hechos son singularmente complejos y cambiantes, a menudo se está tentado de mantener observaciones cualitativas y psicológicas, que varían según los observadores y que en sí mismas no ofrecen ninguna garantía de objetividad. Las ciencias sociales deben partir de datos indiscutibles y que se impongan a todos: tales son las cifras estadísticas equivalente a la experimentación en el campo de las ciencias físicas" 47.

Se comprende, pues, que Halbwachs se muestre hermético y desconfiado respecto al cauce metodológico plural que confeccionan incesantemente los sociólogos chicagüenses, con un cierto aire de bricolaje. No se siente seducido en absoluto por las exploraciones idiográficas, encauzadas desde prácticas sin una forma definida o de inercia ajena, del tipo observación participante, entrevistas, historias de vida o análisis de documentos personales (la correspondencia privada, las cartas a los periódicos que Thomas y Znaniecki habían explotado en The Polish Peasant) ${ }^{48}$. Se antojan modos demasiado interpretativos y próximos a la ligereza narrativa del periodismo ${ }^{49}$. Por lo mismo no da más importancia a la confección

46 Precisamente junto con F. Simiand, su mentor y amigo en el círculo de l'Année, Halbwachs es el más apto e interesado en el uso de estadísticas en la sociología, que aplican al estudio de la economía y la demografía. Ya hemos expuesto antes su interés en optar por una cátedra de Sociología estadística. Su dedicación y buen hacer lo llevan a participar en el Instituto Internacional de Estadística desde 1935, miembro de la Sociedad Estadística de París y delegado francés en la Conferencia de Estadísticos del Trabajo en 1936 y después en 1938.

47 Halbwachs, M. La statistique et les sciences sociales en France, 1931 Praga. En Le point du vue du nombre, [1936] 2005 p. 369-380.

48 Se trata de un cauce metodológico que podríamos decir "embrionario", abriendo el campo analítico y la recolección de experiencias, y que en ciertos casos posee un aire híbrido (con la antropología, con el periodismo de investigación de la época). En tanto que, forjándose, no posee ni la denominación ni la sistematización de la práctica formal: por ejemplo, la "observación participante" es empleada por Anderson en su monografía The Hobo (1923), junto a las historias de vida, entrevistas y elementos autobiográficos, pero en rigor la forma reconocible y su denominación es muy posterior, teniendo en William F. White (Street Corner Society, 1943) una referencia inexcusable.

49 Sobre las relaciones de la sociología y del periodismo en la trayectoria y obra de Robert Park vid. Martínez, E. (2016). Así como en EE.UU. hay una cierta afinidad y a veces son géneros que pueden fundirse en un escrito, sin que importunen los aportes inclasificables del periodismo, Halbwachs los separa con nitidez. De ahí que los 
cartográfica típica de las descripciones de las áreas naturales y culturales de la ecología, sin duda una de sus grandes aportaciones, pasando por alto el valor ilustrativo y analítico de la representación de indicadores socio-espaciales.

La investigación de gabinete y tratamiento de datos tiene también sus límites. Posiblemente una cercanía a los grupos, un menor desdén hacia su contacto y mayor distancia intelectual respecto a las guías superficiales que dirigen algunos de sus trayectos y observaciones le habrían permitido calibrar la realidad inmediata de un país sacudido por la Gran Depresión. Respecto al crecimiento urbano pensemos que la crisis fue de tal envergadura que hizo bascular el sentido de los flujos migratorios justo cuando Halbwachs hablaba de ellos: la población abandonaba las grandes ciudades para ir a las zonas rurales en busca de medios de vida y por primera vez fue mayor el número de emigrantes que de inmigrantes ${ }^{50}$.

\section{Recepción americana: Halbwachs, la morfología social y la neo- ecología humana}

Lejos de la presunción con que ciertos autores han celebrado el encuentro de ambas corrientes de pensamiento, encarnado en la figura de Halbwachs, en lo que respecta al desarrollo disciplinar su alcance parece más bien modesto y en ocasiones abiertamente decepcionante. El juicio ponderado de Topalov (2012) en su meticuloso estudio le resta trascendencia; y Chapoulie (2013), buen conocedor de la tradición de Chicago, se muestra pesimista al presentarlo rotundamente como una oportunidad perdida. Es cierto que a su retorno las investigaciones morfológicas cobran un nuevo impulso en la agenda de Halbwachs: en 1938 publica Morfología social y son varios los estudios consagrados a las cuestiones demográficas y urbanas. Pero incluso en este caso, cuando aborda el estudio de la estructura urbana de Berlín o el crecimiento de Estambul, o al postular una comparación entre las estructuras morfológicas de las grandes ciudades mundiales (Congreso de Bucarest 1939) se advierte que no incorpora referencias ecológicas de ningún tipo. Esa es una vía muerta; más aún las dimensiones cualitativa y etnográfica de los chicagüenses, que se le antojaban problemáticas. E incluso al abordar la cuestión racial en Le point du vue du nombre (frente a las discutibles tesis de la demografía alemana), no hay referencias a los planteamientos parkianos sobre la experiencia étnica americana.

Además de las que ya han sido mencionadas, las razones que explican que los aspectos originales de las aportaciones chicagüenses y su significación sociológica escapen al reconocimiento de Halbwachs son varias de acuerdo con Chapoulie (2013): las concepciones discordantes de la estructura social que tienen los sociólogos americanos y franceses -los

textos que prepara para Le Progres de Lyon aunque versen sobre las mismas cuestiones, se escriban en otro registro, con otra finalidad, distinta exigencia: es otro medio (divulgativo, no científico).

$50 \mathrm{Ph}$. Blom, La fractura. Vida y cultura en Occidente 1918-1938, 2016, p. 345. Según sus datos en 1921 la migración neta (inmigración menos emigración) había sido de 557.000 personas; en 1925, un año después de la Ley de Inmigración, la cifra fue de 201.000. Pero en 1931, con el país golpeado por la Depresión, reconociendo la derrota, emigraron de los EE.UU. 68.000 personas más de los que llegaron. 
primeros privilegian el lado étnico (grupos) y los segundos una aproximación en términos de clase social; las diferentes aspiraciones y formas de constitución disciplinar: para Halbwachs la legitimidad de la sociología pasa por la medición y la estadística mientras que la aportación de Park y de esa generación de investigadores es el enfoque etnográfico (sin renunciar a otros desarrollos); podríamos considerar además la distancia entre los universos sociales, culturales y académicos de los investigadores implicados, que dificultó su comprensión mutua.

Del lado americano, la recepción de los estudios morfológicos de Halbwachs es prácticamente nula, su contribución pasa desapercibida en ese primer momento. Sólo McKenzie parece interesado en los trabajos realizados por Halbwachs sobre París, pero sin mayor insistencia (y quién sabe si declara su interés con la misma simulada desenvoltura con que Halbwachs elogiaba su afán con las chinchetas). A partir de 1930 la ecología urbana de Park y Burgess pierde presencia en el campo de la sociología general y urbana, pero ni siquiera Louis Wirth -que da continuidad a esa generación de la escuela de Chicago- repara en los trabajos de Halbwachs cuando en su célebre "Urbanism as a way of life" (1938) recoja la contribución de Durkheim (junto a la de Weber y Simmel) para construir una definición sintética de la ciudad en sentido sociológico y la formación de la cultura urbana. Su visión del fenómeno urbano atendiendo a los dos niveles (la estructura material formada sobra una base demográfica, una tecnología y un orden ecológico; el sistema de organización social con una estructura social, instituciones y un modelo de relaciones sociales característicos) revela correspondencias claras con los presupuestos morfológicos, pero sin especificar autoría. Es más, en el planteamiento del "modo de vida" urbano, Wirth no alude ni considera un concepto relativamente próximo como el de "genre du vie" que empleaba Halbwachs en Las causas del suicidio (1930) para hablar de la civilización urbana y/o rural como universos específicos según su base morfológica y psicología colectiva.

En su investigación sobre los orígenes de la sociología ambiental, donde retoma los cauces convergentes de la neo-ecología humana y la morfología social en la configuración de esta subdisciplina, Philippe Boudes (2011) recuerda que hubo que esperar más una década para que algunos comentaristas norteamericanos reivindicaran la relación precisa entre ambas corrientes de pensamiento e investigación y el trabajo de Halbwachs saliera a la superficie. El caso más notable fue el de Llewelyn y Hawthorn (1947) insistiendo en que los problemas sociales sobre los que la ecología humana se interesa "se incluyen (...) en eso que Durkheim, Halbwachs y sus discípulos comprenden bajo la morfología social"51. Esta identificación es reclamada asimismo en el ya clásico "Social Morphlogy and Human Ecology" (1958) de Leo F. Schnore, que identifica abiertamente la morfología y la ecología, la similitud de planteamientos entre Park y Halbwachs:

"Además de prolongar los análisis de Durkheim sobre el suicidio y las 'representaciones colectivas' la morfología social de Halbwachs reclama ampliamente la visión de su mentor y -al mismo tiempo- incorpora una perspectiva ecológica que es a menudo similar a la de Park" (Schnore 1958, 631).

51 Llewelyn y Hawthorn 1947, p. 477. 
En la determinación de esa cercanía entre las perspectivas neo-ortodoxas y la morfología social, sin embargo, la referencia básica no es tanto Halbwachs como el II libro de La división social del trabajo de Durkheim, que se asume como canon.

"La relevancia del pensamiento durkheimiano sobre la ecología moderna es muy claro. Trabaja esencialmente con el mismo tipo de factores, tomando uno de ellos (la estructura) como la variable dependiente. Y su modo de análisis es muy similar al que emplea normalmente la teoría ecológica. El tratamiento de la diferenciación de Hawley sigue el de Durkheim, y hay un obvio paralelismo formal entre la tipología entre la solidaridad mecánica y orgánica y los conceptos de comensalismo y simbiosis, grupos categóricos y corporativos, comunidades independientes y dependientes en el trabajo de Hawley" (Schnore 1958, 630).

Esto ejemplifica no tanto el desconocimiento real de la valía y alcance del trabajo de Halbwachs, auténtico artífice de la morfología social, como la necesidad por parte de la neoecología de procurarse filiaciones o correspondencias de mayor empaque, como Durkheim, al mismo tiempo que se alejan de la ecología humana clásica de Chicago. En lo que respecta a su contribución al estudio ecológico urbano, la exposición que prologa la traducción al inglés de la Morfología Social de Halbwachs, Duncan \& Pautftz (1960, 20-21) sí hace explícita la evidente afinidad entre la morfología y la ecología, si bien en un sentido más temático que propiamente intelectual. De hecho creían identificar en el estudio de Halbwachs sobre el crecimiento de París una anticipación de los modelos de crecimiento urbano típicos de los ecólogos (el modelo de crecimiento zonal, el modelo sectorial y el de los núcleos múltiples). De la misma forma el complejo ecológico de Duncan está adelantado en los componentes morfológicos del análisis típico de Halbwachs (factores demográficos, tecnológicos y ambientales). Es precisamente en este registro como Halbwachs es mayoritariamente contemplado en el campo ecológico, en su aportación a la demografía (la morfología social en sentido estricto) como herramienta básica de la investigación social. Así se deduce también del trabajo de Philip M. Hauser, (Universidad de Chicago) en su estudio "Demography in relation to Sociology" (1959).

\section{Conclusiones}

Al ponderar los resultados efectivos del intercambio entre autores y corrientes de pensamiento no es infrecuente que las perspectivas iniciales, por prometedoras que pareciesen, se frustren al poco de asomar. Desfases temporales, instituciones arraigadas a contextos sociales particulares, trayectorias intelectuales insólitas..., las afinidades presumidas no bastan para componer un arreglo provechoso entre los partícipes, dejando aparte el hecho de que las posibilidades de éxito dependen también de las disponibilidades técnicas, financieras y humanas. En cierto modo es lo que sucede al considerar el ambivalente encuentro de la ecología humana y la morfología social operado en la estadía de Halbwachs en Chicago.

También es ambivalente la consideración del encuentro entre los académicos franceses. Se identifican en ese sentido dos tiempos a los que corresponden interpretaciones diferentes: en un primer momento sobresale una lectura satisfecha que plantea la conexión categórica entre ambas líneas analíticas; no es sólo el entendimiento con el entorno 
intelectual americano, es la presunción de la existencia de propuestas complementarias así como la afirmación -sutil en un segundo plano- de la universalidad y relevancia de la sociología francesa. La segunda interpretación es más descreída e inclemente, construida sobre la base del acceso a un amplio abanico de documentos privados y públicos, textos y escritos que han acreditado un conocimiento más minucioso del encuentro citado. Estos permiten calibrar a la baja tanto el alcance de la "misión institucional" de Halbwachs en Chicago como el intercambio intelectual. Si nos situamos en el plano de la relación institucional el resultado es poco fructífero, aunque las razones son más complejas de lo que hemos podido desarrollar aquí. Halbwachs, que había expresado la voluntad de aprender del empuje de la universidad americana en el marco de la restitución de los estudios sociológicos en Francia, procuró a su regreso, junto a Bouglé, poner en práctica algunas de las ideas surgidas de sus respectivas experiencias y contactos. Pero sería un esfuerzo infructuoso: la propia Fundación Rockefeller evita su compromiso ante la falta de concreción de las propuestas de los durkheimianos. También ha cambiado el contexto: la crisis del 29 deja sentir sus efectos e impacta en la suficiencia financiera de la FR. Aun así otorgó diversas ayudas y subvenciones destinadas al Institut d'Ėthnologie y el Centre de Documentation Sociale. Entre las partidas consignadas en 1935 es posible encontrar una subvención concedida a Halbwachs para lo que viene designado como "Travaux de l'Institut francais de Sociologie" y para la edición de los Annales sociologiques, la revista que da continuidad a l'Année sociologique ${ }^{52}$ (será su secretario general al año siguiente y dirigirá la revista entre 1942 y 1944).

En cuanto al plano de la influencia o recepción analítica, como hemos visto, la repercusión no parece mucho mayor. Sobre la introducción, crítica o no, del programa chicagüense en la sociología francesa por parte de Halbwachs da la impresión de que se trata de una reseña erudita elaborada desde la distancia intelectual y cultural. Tampoco puede decirse que diera continuidad a esta vía analítica la base de citas y referencias a la sociología americana, salvo las necesarias al propósito de sus argumentos. En su trabajo sobre la sociología alemana y la americana aprecia ya ese contraste entre el interés alemán por el mundo de las ideas y el avance práctico, casi sin directrices, de los americanos, poco dados a enredarse en conceptos y teorías. La idea de la sociología francesa de Halbwachs (y de Mauss, Bouglé o Simiand) se reafirma en la investigación empírica y racional, fundamentada en las buenas teorías y en las herramientas estadísticas, alejada de devaneos especulativos o exposiciones idiográficas. Por eso no se reconoce en el planteamiento de la etnografía urbana de Chicago y enlaza mejor con los propósitos cuantitativistas de Ogburn. Y por eso, la neoecología americana, que también deja atrás las referencias etnográficas chicaguenses, se encuentra cómoda en la referencia morfológica francesa que a decir de Topalov (2012) toma como un antecesor europeo que le da tono.

52 Las referencias completas del montante de las ayudas y destinatarios vienen expresadas en el trabajo de Brigitte Mazon 1985, p 332 y ss. 


\section{Bibliografía}

Becker, Annette. 2003. Maurice Halbwachs, un intellectuel en guerres mondiales (1914-1945). París: Agnes Viént Éditions.

Berr, Henri. 1921. "L'Esprit de synthèse dans l'enseignement supérieur. L'Université de Strasbourg." Revue de synthèses historique, 23.

Blom, Phillip. 2016. La fractura. Vida y cultura en Occidente 1918-1938. Barcelona: Anagrama. Boudes, Philippe. 2011. "Morphologie sociale et sociologie de l'environnement: l'apport de Halbwachs à l'étude des relations entre les sociétés et leur milieu natural." L'Année sociologique 61: 201-224

Chapoulie, Jean-Michel. 2001. La tradition sociologique de Chicago (1892-1961). Paris: Seuil.

Chapoulie, Jean-Michel. 2013. "Halbwachs et Chicago: un rendez-vous manqué." Métropolitiques, 8 mars 2013. URL: http://www.metropolitiques.eu/Halbwachs-et-Chicago-un-rendez.html

Chesnau, Isabelle y Roncayolo, Marcel. 2011. L' Abecedaire de Marcel Roncayolo. Entretiens. París: Infolio.

Chombart de Lauwe, Paul Henry et al. 1952. Paris et l'agglomération parisienne. L'Espace social dans une grande cité (I). París : PUF.

Craig, John E. 1979. "Maurice Halbwachs à Strasbourg.” Revue française de sociologie 20: 273292.

Duncan, O. D. \& Pauftz, H. P. 1960. “Translator's Preface”. En Population and Society. Introduction to Social Morphology, M. Halbwachs. Illinois: The Free Press of Glencoe.

Durkheim, Emile. 1897. “Notes sur la morphologie sociale." L'Année sociologique, II (1897-8): 520-21.

Durkheim, Emile. [1895] 1984. Las reglas del método sociológico. Madrid: Ediciones Morata.

Grafmeyer, Yves y Joseph, Isaac. 2004. L'École de Chicago. Naissance de l'écologie urbaine. París: Ed. Flammarion.

Gurvitch, Georges (ed.). 1958. Traité de Sociologie. Paris : PUF.

Gurvitch, Georges. (ed.). 1963. La vocation actuelle de la sociologie (2 vol.). París: PUF.

Halbwachs, Maurice. 1905. "La ville capitaliste d'après Sombart." Revue d'économie politique 19: 737-747.

Halbwachs, Maurice. 1932. "Chicago: expérience ethnique”, Annales d'histoire économiques et sociales 4: 11-49 [ed. esp. "Chicago, experiencia étnica". En Maurice Halbwachs: Estudios de morfología social de la ciudad. 2008. Ed. de Emilio Martínez. Madrid: CIS, 2008]

Halbwachs, Maurice. [1938] 1970. La Morphologie Sociale. París: Colin.

Halbwachs, Maurice. 1960. Population and Society. Introduction to Social Morphology. Edición inglesa de La Morphologie sociale de O. D. Duncan \& H. W. P. Fautz. Glencoe, Ill.: The Free Press.

Halbwachs, Maurice. 2012. Écrits d'Amérique. (Edición y estudio a cargo de Christian Topalov.) Paris: Éditions de l'ÉHESS. 
Halbwachs, Maurice. [1935] 2005. Le Point de vue du nombre. (Edición crítica a cargo de E. Brian y M. Jaisson). París: INED.

Hauser, Philip M. 1959. "Demography in Relation to Sociology." American Journal of Sociology 65, (2): 169-173.

Heilbron, Johan. 1985. “Les métamorphoses du durkheimisme (1920-1940).” Revue française de sociologie XXVI: 203-237.

Llewelyn, E. \& Hawthorn A. 1947. “L’Écologie humaine.” En La Sociologie au XXe siècle editado por Georges Gurvitch, (1): 477-510. Paris : PUF.

Marcel, Jean-Christophe. 1999. "Maurice Halbwachs à Chicago ou les ambiguïtés d'un rationalisme durkheimien." Revue d'Histoire des Sciences Humaines (1): 47-68.

Martin, Olivier. 1999. "Raison statistique et raison sociologique chez Maurice Halbwachs." Revue d'Histoire des Sciences Humaines (1): 69-101.

Martínez, Emilio (ed.). 2008. Maurice Halbwachs. Estudios de morfología social de la ciudad, Madrid: CIS.

Martínez, Emilio. 2016. “Donde la ciudad se escribe. Prensa, urbanización y cultura en Robert E. Park". OBETS. Revista de Ciencias Sociales 11(2) : 487-512.

Mazon, Brigitte. 1985. "La Fondation Rockefeller et les sciences sociales en France, 19251940." Revue française de sociologie 26 (2): 311-342.

Montigny, Gilles. 2005. Maurice Halbwachs. Vie, ouvres, concepts, París: Ellipses.

Mucchielli, Laurent y Pluet-Despatin, Jacqueline. 1999. "Halbwachs au Collège de France." Revue d'Histoire des Sciences Humaines (1): 179-188

Müller, Bertrand. 2018. "L'université de Strasbourg dans l'immédiat après-guerre (19191925)." Revue d'Histoire des Sciences Humaines (33): 211-240.

Park, Robert E. \& Burgess, Ernest W. 1921. Introduction to the Science of Sociology. Chicago: University of Chicago Press.

Park, Robert E. 1926, "Review of books of L. Febvre, P. Vidal de la Blanche, F. Thomas and R. Mukherjee." American Journal of Sociology 32 (3): 486-490.

Park, Robert E. 1999. La ciudad y otros ensayos de ecología urbana. (Ed. y trad. de Emilio Martínez). Barcelona: Serbal.

Pizza, Antonio y Pla, Maurici. 2012. Chicago- Nueva York: Teoría, arte y arquitectura entre los siglos XIX y XX. Madrid: Abada Ed.

Rhein, Catherine. 2003. "L'écologie humaine, discipline chimère." Sociétés Contemporaines (49/50): 167-190.

Schnore, Leo F. 1985. "Social Morphology and Human Ecology." American Journal of Sociology 63 (6): 620-634.

Tournes, Ludovic. 2007. "La Fondation Rockefeller et la naissance de l'universalisme philanthropique américain." Critique Internationale (35) : 137-197

Tournes, Ludovic. 2008. "La fondation Rockefeller et la construction d'une politique des sciences sociales en France (1918 - 1940)." Annales. Histoire, Sciences Sociales (6): 1371-1402.

Topalov, Christian. 2006. "Maurice Halbwachs et les sociologues de Chicago." Revue française de sociologie 47 (3) : 561-590. 
Topalov, Christian (ed.). 2012. Maurice Halbwachs. Ecrits d'Amérique. París: Éd. EHESS.

Wirth, Louis. 1938. "Urbanism as a way of life." American Journal of Sociology 44 (1): 1-24

(C) Copyright: Emilio Martínez, 2021

(C) Copyright: Scripta Nova, 2021.

Ficha bibliográfica:

MARTÍNEZ, Emilio. (Des)encuentros de Chicago: ecologia humana y morfologia social en la perspectiva de Maurice Halbwachs. Scripta Nova. Revista Electrónica de Geografía y Ciencias Sociales. Barcelona: Universitat de Barcelona, vol. 25, Núm. 2 (2021), p. 241270 [ISSN: 1138-9788]

DOI: $10.1344 / \mathrm{sn} 2021.25 .32410$ 